$\underline{084}$

\title{
Potential of cultivation of Gliricidia (Gliricidia sepium) in coconut triangle for bioenergy generation
}

\author{
L H P Gunaratne and S A Dissanayake \\ Department of Agricultural Economics a Business Management, University of Peradeniya, Sri Lanka.
}

Evaluation of least cost and environmentally friendly energy alternatives is essential to overcome the prevailing energy crisis. Dendro thermal energy generation has been identified as one of the best options due to its potential as a low cost and locally available environmentally sound energy source. However, this potential has not been exploited by the people in most of the potential areas which hinder the further expansion of establishing bio-energy plants. With this background, a study was undertaken to evaluate the present status and the potential of gliricidia (Gliricidia sepium) cultivation in coconut triangle for bio-energy generation. Gliricidia sepium is a multipurpose crop used for wood, fuel wood, fodder and nitrogenous organic fertilizer. The wood is presently used for thermal energy i.e., electricity generation for the national grid (Walapane); electricity generation for off-grid rural electrification (Kakkapalliya, Thanamalwila); industrial heat application (Madampe, Kottawa etc.) and household cooking. The study further attempted to determine the factors associated with the supply of gliricidia for bio-energy generation and attitudes of the coconut growers towards the gliricidia intercropping. Finally, it examined the strengths and weaknesses of the supply as well as demand in order to make sound recommendations to promote gliricidia cultivation in coconut lands for bio-energy generation.

Two field surveys were simultaneously conducted to gather the necessary data. The first survey dealt with the existing suppliers in Anamaduwa area, while the second survey was carried out in Kuliyapitiya area with the potential growers. In addition, a case study was conducted with successful growers. Logit modeling was used to analyze the data.

The study found that the opportunity costs of land and labour of the both sites of study were fairly low. Moreover, the investment on agriculture related activities in marginal coconut lands were extremely low. Further the study revealed that even though there was a positive attitude and high demand for gliricidia cultivation, there is an inadequate supply to the thermal plants for bio-energy generation. The technical information on growing gliricidia for bioenergy generation had not disseminated into the people of the area mainly due to lack of awareness programmes. The results of the logit analysis revealed that income from coconut, total highland availability and willingness to become a contract farmer are significant variables that influence the willingness to cultivate gliricidia. The case study revealed that the cultivation of gliricidia appear to be economically profitable and technically feasible option given that its low input nature, availability of marginal coconut lands, low opportunity cost of labour and less income opportunities available in these areas, Government involvement and having a reasonable price with stable market for gliricidia will encourage the public to enter into this business whereas effective extension service is a must for making people aware.

\section{$\underline{085}$ \\ Hybrid biogas plant producing electricity \\ $\mathrm{R} \mathbf{L}$ Gonsalves and $\mathrm{R}$ Khichadi \\ Shivaji University, Kolhapur, Maharashtra, India}

Energy is the major cause behind the development of a nation. By thinking on it we have worked on the biogas plant and modified it to generate electricity. This generated electric current is sufficient enough to power an entire house. Also our idea can be implemented in country with huge amount of organic waste material.

Have you any time thought of "Just a switch in your house which when in ON condition can fetch you electricity, and in OFF condition can generate biogas". Yes this is absolutely possible and our extreme hard efforts have made us to achieve this successfully.

Proceedings of the International Forestry and Environment Symposium 2006 of the

Department of Forestry and Environmental Science, Univérsity of Sri Jayewardenepura, Sri Lanka 